\title{
Apoptosis-inducing activity of endocrine-disrupting chemicals in cultured PC12 cells
}

\author{
Harue Sasaya $^{1,2}$, Kazuya Yasuzumi ${ }^{1}$, Hiroki Maruoka ${ }^{1,3}$, Ayumi Fujita ${ }^{1}$, Yuichi Kato ${ }^{1}$, Taiki Waki ${ }^{1}$, \\ Koji Shimoke ${ }^{1}$, Toshihiko Ikeuchi ${ }^{{ }^{*}}$ \\ ${ }^{1}$ Department of Life Science and Biotechnology, Faculty of Chemistry, Materials and Bioengineering and Strategic Research Base, \\ Kansai University, Osaka, Japan \\ ${ }^{2}$ Division of Natural Products Chemistry, Institute of Natural Medicine, University of Toyama, Toyama, Japan \\ ${ }^{3}$ Technology Research Laboratory, Kurabo Industries Ltd., Osaka, Japan \\ Email: ${ }^{*}$ ikeuchi@kansai-u.ac.jp
}

Received 20 January 2012; revised 9 February 2012; accepted 29 February 2012

\begin{abstract}
Endocrine-disrupting chemicals (EDCs) are known to exert estrogen-like effects that are similar to those made by naturally produced hormones or by inhibition of the receptors in the cell receiving the hormones. Recently, several reports have indicated that EDCs can affect the developing central nervous system. In our current study, we report that some EDCs induce apoptosis in cultured PC12 cells and can be classified into three groups. Bisphenol A (BPA), pnonylphenol (NP) and tributyltin chloride (TBT) were found to induce endoplasmic reticulum (ER) stress-associated apoptosis and activate the unfolded protein response (UPR) system, whereas benomyl (beno) induced non-ER stress-associated apoptosis. The half-maximal apoptosis-inducing concentrations $\left(\mathrm{IC}_{50}\right)$ of these EDCs were $160 \mu \mathrm{M}$ for BPA, 25.6 $\mu \mathrm{M}$ for NP, $640 \mathrm{nM}$ for TBT and $48 \mu \mathrm{M}$ for beno. Although these concentrations are higher than those found in the environment, some EDCs may have apoptotic effects on various cells in the body, including neurons, through their accumulation in the body over time or condensation through the food chain. On the other hand, benzopyrene, fenvalerate, styrene monomer and bis(2-ethylhexyl)phthalate did not induce apoptosis in PC12 cells. We analyzed also whether apoptosis-inducing EDCs had an estrogen-like effect on cultured PC12 cells transfected with a luciferase reporter plasmid, the activity of which is dependent on estrogen receptor $\alpha$. We found that BPA had an estrogen-like effect $\left(E_{50}=5.9 \mu \mathrm{M}\right)$ but that NP, TBT and beno did not in transfected PC12 cells. These results suggest that BPA may predominantly exert estrogenic effects, but others may predominantly have apoptosis-inducing effects on cells in the body exposed to a polluted environment.
\end{abstract}

Keywords: Endocrine-Disrupting Chemicals; ER Stress; Apoptosis; Estrogen Receptor; PC12 Cells

\section{INTRODUCTION}

Endocrine-disrupting chemicals (EDCs) are believed to exert estrogen-like effects in vivo and mimic the effects of endogenous hormones through a higher binding affinity to the hormone receptors $[1,2]$. In general, EDCs are also considered to accumulate in the body because of their chemical stability. Initial studies in mice and humans have shown that a decreased number of sperm, sterility, an imperfect descent of the testicles and abnormal hyperplasia of the sexual organs may be caused by EDCs [1]. In addition, it has been reported that EDCs may cause cancers, such as breast and prostate cancer, by exerting estrogenic actions [1]. Moreover, it has been suggested that EDCs may influence not only hormonal systems but also the nervous and immune systems. EDCs may also promote the aberrant development of these systems because they are present during key developmental stages and because their high levels may activate pathways that are normally unaffected by physiological levels of these compounds [2].

The developing nervous system is known to be particularly sensitive to the actions of endogenous compounds and steroids and may thus also be particularly sensitive to the deleterious effects of EDCs. Members of the neurotrophin family of growth factors, such as nerve growth factor (NGF), acting through their cognate receptors, the Trks, are critical mediators of neural development and regulate neuronal survival, proliferation and differentiation. Neurotrophin and Trk expression are both regulated by estrogens, suggesting that exposure to EDCs might perturb neuronal survival or differentiation by altering neurotrophin signaling [3].

The endoplasmic reticulum (ER) is a reticulated or-

"Corresponding author. 
ganelle in which proteins are synthesized and modified for proper folding. In normal cells, approximately $30 \%$ of newly synthesized proteins are unfolded [4] and a portion of these proteins may become correctly folded through the assistance of ER chaperones such as glucose-regulated protein 78 (GRP78). The remaining unfolded proteins accumulate in the ER and can cause ER stress. Under such ER stress conditions, an adaptive self-defense response, termed the unfolded protein response (UPR) is triggered to decrease the unfolded protein load. Several cellular events, such as a high demand for protein secretion $[5,6]$ and the onset of missense mutations, enhance protein unfolding and thus lead to ER stress. A critically high accumulation of unfolded proteins is potentially fatal to the cell.

Recent and extensive studies on the mammalian UPR system have identified three types of ER resident stress sensors, ATF6, Ire1 and Perk [4,5,7]. Under normal conditions, all three sensors remain inactive when associated with the ER chaperone, GRP78, via their luminal domains. Once ER stress occurs, GRP78 dissociates from these sensors to engage in folding the accumulated unfolded proteins in the ER. As a consequence, free Ire1 and Perk oligomerize and autophosphorylate, which results in their activation [4,5]. After the dissociation of GRP78 from the luminal domain, ATF6 translocates to the Golgi apparatus and is cleaved by the proteases S1P and S2P, resulting in its activation as a transcription factor [7-9]. When ER stress becomes severe, apoptotic cell death is induced, referred to as ER stress-mediated apoptosis, during which caspase-12, an ER stress-specific caspase, is cleaved.

An important regulatory step in apoptosis occurs at the mitochondria where members of the $\mathrm{Bcl}-2$ family proteins promote or prevent a membrane permeability transition. Signaling events that act upstream of the mitochondrial changes during neuronal apoptosis are not yet fully understood but may include the activation of a caspase cascade and the cleavage of Bid, which in turn mediates mitochondrial dysfunction and the release of apoptotic factors from this organelle. In addition, poly (ADP-ribose) polymerase (PARP) and p53 have been identified as key factors of early apoptotic signaling in neurons acting upstream of mitochondrial damage and the activation of caspases.

$P$-Nonylphenol (NP) is a degradation product of a group of nonionic surfactants called nonylphenol ethoxylates (NPEs), which are used globally in the production of plastics, pesticides and cleaning products, and are present in sewage effluents around the world [3]. NP is more persistent in the environment than its parent NPE molecule. The prevalence of NP and NPE in both aquatic environments and in water has been reviewed recently and the current research has identified NP as the most important degradation product of NPE due to its enhanced resistance to biodegradation, its toxicity and its estrogenicity [10].

Bisphenol A (BPA) is a small estrogenic monomer that is polymerized to produce polycarbonate plastic resins that are used to line metal cans $[11,12]$. BPA is also used in other types of plastic, such as polyvinyl chloride (PVC), used in the manufacture of medical tubing, toys and water pipes, and polyethylene terephthalate (PET), which is used in soda and mineral water bottles. BPA is also used to make dental sealants and the total worldwide production levels of this chemical exceeded 6 billion pounds in 2003. BPA is therefore one of the highest volume chemicals produced globally. Brominated BPA is a major flame retardant and is also a known EDC. It has been known for decades that BPA can affect tissues and it has recently been shown to also antagonize the actions of thyroid hormone and androgen. However, BPA acts as an agonist for a mutant form of the androgen receptor found in some prostate cancer cells [1].

Tributyltin chloride (TBT) is an environmental pollutant that is most widely used as a biofouling agent for paints and for coating structures exposed to the aquatic environment, such as ships, oil rigs and water intake pipes [13]. The bioaccumulation of TBT occurs in aquatic species and other wildlife due to its lipophilic and ionic properties, and also its slow rate of elimination from these organisms. TBT enters the human food chain mainly through contaminated marine and freshwater species, industrial effluents, from its domestic use as a wood preservative, leaching from PVC pipes, and inhalation and absorption through the skin.

Benomyl (beno) (methyl[1-[(butylamino)carbonyl]-1Hbenzimidazol-2-yl]carbamate) is a benzimidazole fungicide widely used on food crops and ornamental plants $[14,15]$. In the natural environment as well as in biological systems, beno is predominantly metabolized to carbendazim (methy-2-benzimidazole carbamate) [15-18]. Both beno and carbendazim are fungicidal through the inhibition of microtubule assembly by the tubulins $[19$, 20]. Beno is also known to cause adverse effects on the male reproductive system, including decreased testicular and epididymis weights, and reduced epididymis sperm counts and fertility in rats [21,22]. Despite its reproductive toxicity, the affinity of beno for steroid receptors is controversial. Some studies have demonstrated that beno has no estrogenic activity in vitro [23] and reported that male reproductive toxicity in rats is caused by disruptions to microtubule assembly and probably not via a steroid-mediated mechanism [24,25]. In addition to its reproductive effects, beno causes developmental defects such as malformed neural tissue in Xenopus embryos [26], and a decrease in the yolk sac diameter, crownrump length and parameters of differentiation, including 
the morphological score, have been reported in rat embryos exposed to this compound in vitro cultures [27]. Some studies have also demonstrated the estrogenic potential of beno based on zebrafish brain aromatase gene induction. In zebrafish embryos, beno has shown toxic effects that correspond to those found in beno-treated rodents [27].

In our current study, we investigated the apoptosisinducing activity of specific EDCs in cultured PC12 cells. We found that BPA, NP and TBT induce ER stress-associated apoptosis and activate the UPR system, but that beno induces non-ER stress-associated apoptosis. These EDCs were also found to influence the expression of Bcl-2 family proteins acting in the mitochondrial pathway. We further found that BPA has estrogenic activity, but that NP, TBT and beno do not, using cultured PC12 cells transfected with a luciferase reporter plasmid whose expression is dependent on the activation of estrogen receptor $\alpha$. These results suggest that BPA mainly exerts estrogen-like effects, but that the other EDCs tested may predominantly exert apoptosis-inducing effects, on cells in the body.

\section{MATERIALS AND METHODS}

\subsection{Reagents}

Bisphenol A, $p$-nonylphenol and tributyltin chloride were purchased from Wako Pure chemicals (Tokyo, Japan). Anti-GAPDH antibody was purchased from Millipore (Billerica, MA). Anti-cleaved caspase-3, anti-Bax, antiBim and anti-Puma antibodies were purchased from Cell Signaling (Beverly, MA). Anti-GRP78, anti-Bcl-2 and anti-caspse-12 antibodies were purchased from Santa Cruz Biotechnology (Santa Cruz, CA). Anti-Bcl-xL was purchased from Sigma-Aldrich (St. Louis, MO). AntiMcl-1 was obtained from Acris Antibody GmbH (Herford, Germany). Anti-GAPDH was purchased from Chemicon (Temecula, CA).

\subsection{Cell Culture}

PC12 cells were maintained in Dulbecco's modified Eagle's medium (DMEM) supplemented with $5 \%(\mathrm{v} / \mathrm{v})$ fetal bovine serum (FBS) and $5 \%(\mathrm{v} / \mathrm{v})$ heat-inactivated horse serum (HS). To measure cell viability, cells were seeded onto collagen-coated 96-well plates at a density of $1 \times 10^{5} \mathrm{cells} / \mathrm{cm}^{2}$. The medium was changed on the following day to serum-free DMEM (SF-DMEM), and each EDC was added at this time point if required. Twenty-four hours after the addition of the reagents, cell viability was measured.

\subsection{Measurement of Cell Viability}

Viable cells were quantified using the MTT assay.
Briefly, cells were seeded onto 96-well plates and the medium was changed to SF-DMEM containing each EDC. After cultivation for $24 \mathrm{~h}$, the medium was changed to SF-DMEM containing 5\% (v/v) MTT solution and cells were incubated for a further $2 \mathrm{~h}$. Fluorescence intensity was detected by spectrophotometry at $750 \mathrm{~nm}$. Cell viability was defined as (test sample count) - (blank count)/(untreated control count) - (blank count) $\times 100$.

\subsection{Immunoblotting Analysis}

PC12 cells were seeded onto $6 \mathrm{~cm}$-diameter dishes, and the medium was changed on the following day to SF-DMEM containing each EDC or tunicamycin (Tm). After cultivation for $24 \mathrm{~h}$, the cells were lysed in lysis buffer as described previously [28]. Total lysate (20 $\mu \mathrm{g}$ per lane) was loaded on SDS-PAGE and blotted onto a PVDF membrane using a semi-dry blotter (Atto, Tokyo, Japan). The primary antibody was loaded onto the membrane after blocking with skin milk (Nacalai Tesque, Kyoto, Japan), and this was followed by incubation with A horseradish peroxidase-conjugated secondary antibody for $1 \mathrm{~h}$. Bands were detected and visualized using a light capture system (Atto) and SuperSignal West Femto (Pierce/Thermo Scientific, Rockford, IL).

\subsection{Transfection}

The expression plasmid pGLrER $\alpha$ was kindly provided by Dr. M. Takeyoshi (Chemicals Evaluation and Research Institute, Tokyo, Japan). And the expression plasmid pEGFP-CFTR $\Delta 508$ was kindly provided by Dr. Ron R. Kopito (Department of Biology, Stanford University, Stanford, CA). PC12 cells were grown to $50 \%-60 \%$ confluence and transfected with these expression plasmids using Lipofectamine 2000 (Invitrogen, Carlsbad, CA). The transfected cells were cultured for $48 \mathrm{~h}$ and the medium was then replaced with serum-free DMEM. EDCs were added at this time point as necessary. The cells were collected after further cultivation for $24 \mathrm{~h}$.

\subsection{Dual Luciferase Assay}

PC12 cells were washed twice with PBS, and lysed in $100 \mu \mathrm{l}$ of $1 \times$ Reporter lysis buffer (Promega, Madison, WI). Complete cell lysis was achieved using one freezethaw cycle of $-80^{\circ} \mathrm{C}$ followed by a rapid thawing at $37^{\circ} \mathrm{C}$. The lysates were transferred to the new tube and assayed using the Dual Luciferase assay system (Promega) and TD 20/20 luminometer (Turner Designs, Sunnyvale, CA), in accordance with the manufacturer's instructions.

\subsection{Flow Cytometry}

Strongly GFP-positive cells were evaluated by flow cy- 
tometry (Canto II; Becton Dickinson, Franklin Lakes, NJ). The expression of EGFP-CFTR $\Delta 508$ was detected at $488 \mathrm{~nm}$. Data were processed using FACS Diva software (Becton Dickinson, San Jose, CA). Cells were analyzed for forward and side scatter, and for PI and GFP fluorescence $(488 \mathrm{~nm})$. Dead cells were excluded by gating the forward and side scatter and by eliminating PI-positive cells harvested via background fluorescence. The results were expressed as the percentage of the number of strongly GFP-positive cells among the PInegative cells, after normalizing the relative values to the control value (1.0) determined for cells not exposed to EDC.

\subsection{Statistical Evaluation}

All values are expressed as the mean \pm SEM. The Student's t-test or Tukey's test was used to compare means between groups. $\mathrm{P}$ values of $<0.05$ were considered significant.

\section{RESULTS}

In addition to normal compounds with estrogenic activities found in both sexes as well as at different life stages, humans and animals are exposed to environmental products that mimic estrogenic activity known as endocrinedisrupting chemicals (EDCs). Estrogens have widespread biological functions in the central nervous system (CNS) including the coordination of developmental processes, the regulation of cell physiology and the control of neuroendocrine systems [29]. Estrogens also affect areas of the brain that are not primarily involved in reproduction, such as the basal forebrain cholinergic system, the hippocampus and cerebral cortex, the caudate-putamen, midbrain raphe, brainstem locus cerulean and the spinal cord [30,31]. The PC12 cell line has been used extensively as a model for studying neuronal signaling pathways and neuronal differentiation. PC12 cells respond to neurotrophic factors such as NGF and fibroblast growth factor, and their differentiation into sympathetic neuronlike phenotypes is characterized by neurite outgrowth and the expression of many neuronal specific proteins.

We investigated whether certain EDCs can induce apoptosis in cultured PC12 cells and accordingly classified these compounds into two or three groups. It is well known that tunicamycin (Tm) induces ER stress-mediated apoptosis in various cells. We previously reported that the cleavage of caspase-12, which is known as an ER stress-specific caspase [32], is involved in the progression of Tm-mediated apoptosis in cultured PC12 cells [28]. To further elucidate the characteristics of the EDC-induced effects on PC12 cells, we measured the viability of $\mathrm{PC} 12$ cells treated with different concentrations of BPA, NP, TBT or beno for 24 hours using the
MTT assay (Figure 1). Hoechst 33258 staining was also performed (Figure 2) to detect chromatin condensation, a typical marker of apoptosis. We found from this analysis that apoptosis was induced with an $\mathrm{IC}_{50}$ of $160 \mu \mathrm{M}$ for BPA, $25.6 \mu \mathrm{M}$ for NP, $640 \mathrm{nM}$ for TBT and $48 \mu \mathrm{M}$ for beno (Figures 1(a)-(d)) (Table 1). Apoptotic condensed chromatin was detected in the presence of BPA, NP, TBT or beno (Figure 2).

On the other hand, benzopyrene, fenvalerate, styrene monomer or bis(2-ethylhexyl)phthalate among the EDCs tested in this study did not induce apoptosis in PC12 cells at the maximal concentrations that could be prepared (Table 1).

We next performed immunoblotting of proteins which are known to be upregulated or cleaved during ER stress. We observed in this analysis that the first three of four apoptosis-inducing EDCs upregulated the expression of glucose-regulated protein 78 (GRP78) and also induced the cleavage of caspase-12 (Figures 3(a)-(c)). During ER stress, cells activate the unfolded protein response (UPR) system and cleave ER stress-specific caspase-12. Our results thus suggested that BPA, NP and TBT induce ER stress-associated apoptosis in PC12 cells. On the other hand, beno was found not to upregulate the expression of GRP78 (data not shown), indicating that it induces nonER stress-associated apoptosis. This finding suggested that beno may directly trigger mitochondrial dysfunction, leading to cytochrome c release, and then induce an ordinary apoptotic response. It has been reported that apoptosis can be classified into at least two types, ordinary and ER stress-mediated [3]. Cleaved caspase-12 is considered to activate a caspase cascade involving caspase-3 and -9. We therefore investigated whether the four apoptosis-inducing EDCs in our panel also activated caspase-3.

Table 1. Values of half-maximal apoptosis-inducing concentrations $\left(\mathrm{IC}_{50}\right)$ of EDCs in PC12 cells.

\begin{tabular}{cc}
\hline EDC & $\mathrm{IC}_{50}(\mu \mathrm{M})$ \\
\hline $\mathrm{BPA}$ & $160(161.1 \pm 7.9)$ \\
$\mathrm{NP}$ & $25.6(25.0 \pm 1.4)$ \\
$\mathrm{TBT}$ & $0.64(0.64 \pm 0.04)$ \\
beno & $48(47.5 \pm 4.0)$ \\
benzopyrene & $>100$ \\
fenvalerate & $>100$ \\
styrene monomer & $>1000$ \\
bis(2-ethylhexyl)phthalate & $>1000$ \\
\hline
\end{tabular}

$\mathrm{IC}_{50}$ values of BPA, NP, TBT and beno were obtained from Figures 1(a)-(d). In parentheses, values of the means \pm SEM $(\mathrm{n}=7)$ are also shown. The concentrations used for benzopyrene, fenvalerate, styrene monomer and bis(2-ethylhexyl)phthalate were the highest concentrations that could be prepared. 


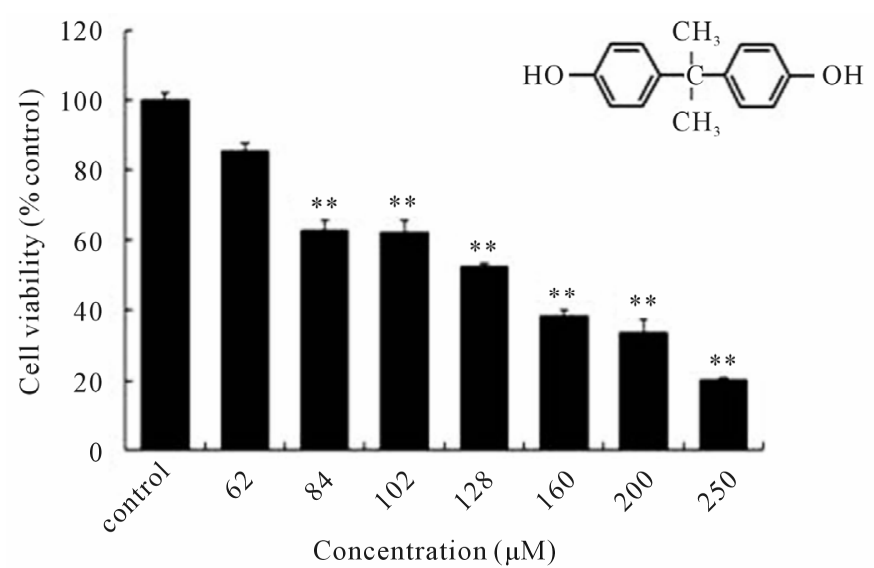

(a)

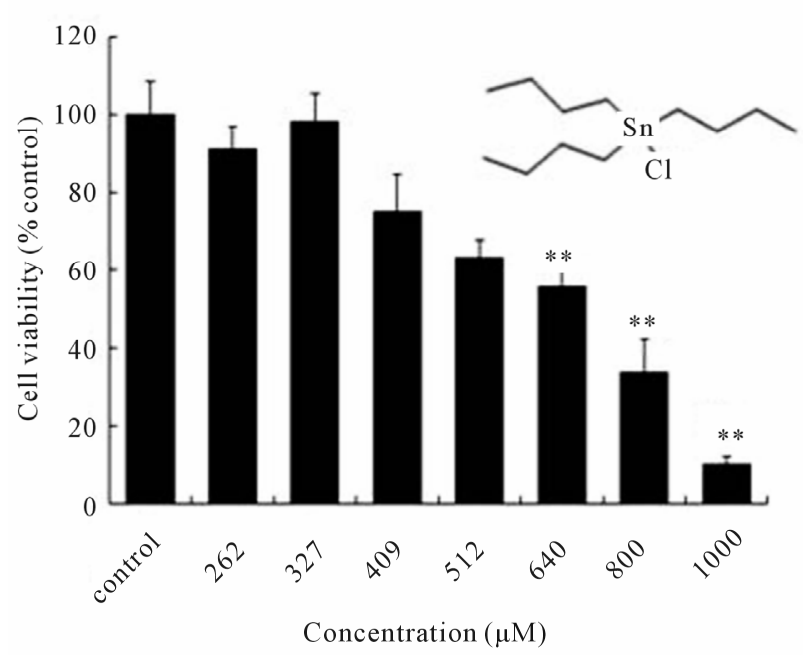

(c)

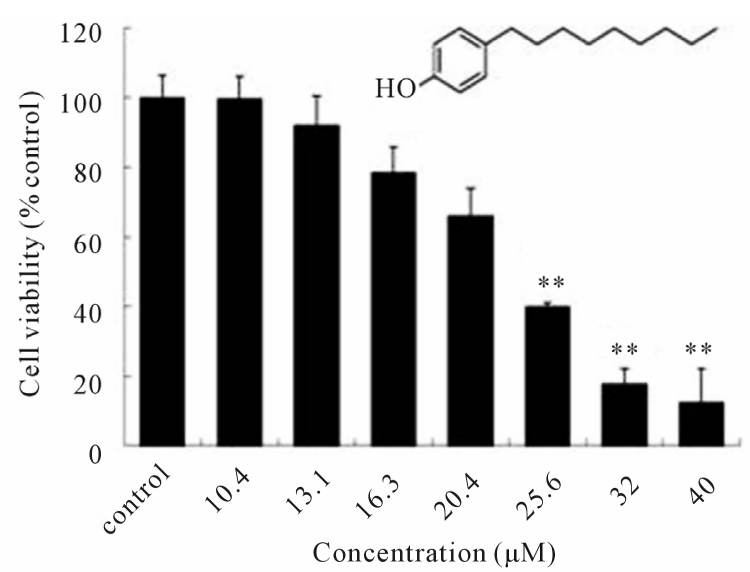

(b)

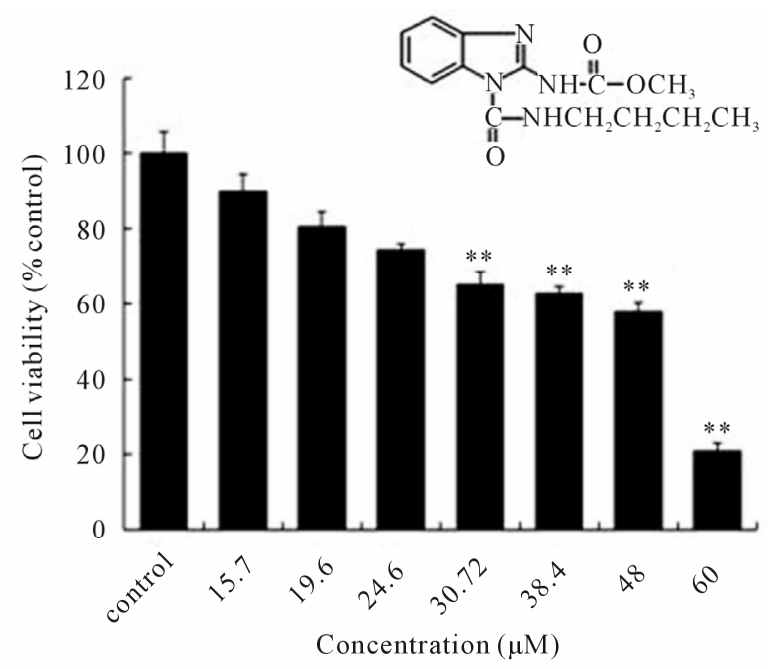

(d)

Figure 1. Some EDCs induced cell death in a dose-dependent manner in PC12 cells. PC12 cells were cultured for $24 \mathrm{~h}$ without (control) or with the indicated EDC in serum-free DMEM, and viable cells were quantified using the MTT assay. Cells were treated with (a) Bisphenol A (BPA); (b) p-nonylphenol (NP); (c) Tributyltin chloride (TBT); or (d) Benomyl (beno). The final concentration of each compound is indicated. The values shown are the means \pm SEM $(n=5)$. Differences between groups were examined for statistical significance using Tukey's test. ${ }^{* *} \mathrm{P}<0.01$ vs. control.

We found that BPA, NP and TBT, but not beno, activate caspase-3 in PC12 cells (Figures 3(a)-(c) and data not shown). Caspase-3 is an effecter caspase for all types of apoptosis. At present we are uncertain why caspase-3 was not activated during beno-induced apoptosis. It has been reported that caspase-3 catalyses the proteolytic cleavage of poly(ADP-ribose) polymerase (PARP), a 116 $\mathrm{kDa}$ nuclear enzyme closely linked to apoptosis [3]. We further found in this regard that BPA, NP and TBT induce the cleavage of PARP in PC12 cells, whereas beno did not have this effect (Figures 3(a)-(c) and data not shown).

We performed immunoblotting of Bcl-2 family proteins in lysates from PC12 cells individually treated with each EDC. BPA increased the expression of the proapoptotic Bcl-2 family Puma, whereas NP or TBT did not (Figures 4(a)-(c)). NP increased the expression of pro-apoptotic Bax, but BPA and TBT did not. NP and TBT, but not BPA, increased the expression of Bim. On the other hand, NP treatment upregulated the expression of the anti-apoptotic proteins Bcl-2 and Bcl-xL, but BPA and TBT did not exert this effect (Figures 4(a)-(c)).

These results indicate that different Bcl-2 family proteins are upregulated by distinct EDCs, suggesting that different signaling mechanisms are involved in the ER stress-associated apoptosis triggered by different EDCs (Figures 4(a)-(c)). During apoptosis, Bax undergoes a conformational change and is translocated from the cytosol to the outer mitochondrial membrane, where it triggers cytochrome $\mathrm{c}$ release. Cytochrome $\mathrm{c}$ then induces apoptosome formation, leading to the activation of the initiator caspase-9 and effector caspase-3 [33,34]. In 
control

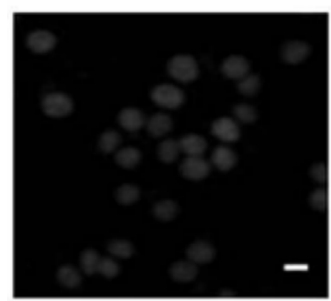

$9.10 \pm 0.12$

NP

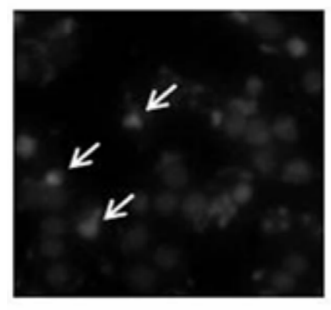

$2.44 \pm 0.08$

Benc

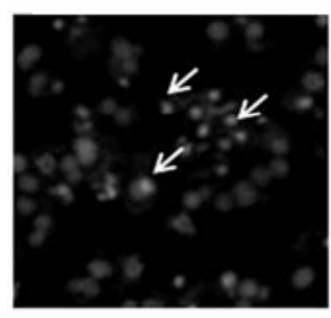

$3.21 \pm 0.07$

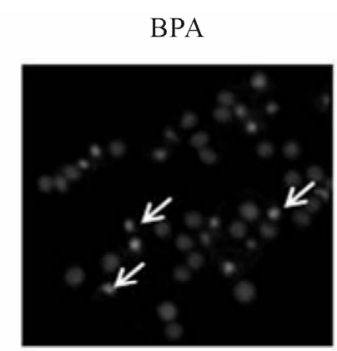

$2.74 \pm 0.08$

TBT

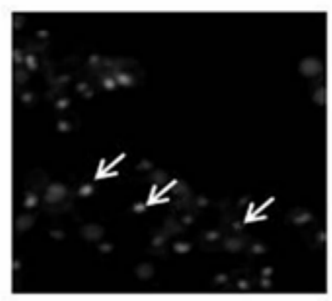

$2.36 \pm 0.07$

$\operatorname{Tm}$

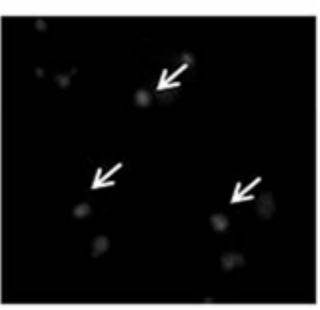

$2.40 \pm 0.08$

Figure 2. Hoechst 33258 staining of EDC-treated PC12 cells. PC12 cells were plated in 8-well chamber plates and cultured for $24 \mathrm{~h}$ without (control) or with each EDC in serum-free DMEM. The cells were then fixed and stained with $1 \mu \mathrm{g} / \mathrm{ml}$ Hoechst 33258 dye in phosphate-buffered saline (PBS) for 30 min. The EDC concentrations in the cultures were $160 \mu \mathrm{M}$ BPA, $25.6 \mu \mathrm{M} \mathrm{NP}, 640 \mathrm{nM}$ TBT and $48 \mu \mathrm{M}$ beno. Apoptotic chromatin condensation can be detected by this staining. Arrows indicate typical apoptotic nuclei with condensed chromatin. As a positive control experiment, cells were cultured with 1 $\mu \mathrm{g} / \mathrm{ml}$ tunicamycin $(\mathrm{Tm})$. Values $(\mu \mathrm{m})$ of nuclear diameters measured are shown below each photographic image. In a negative control (control), diameters of nuclei without condensed chromatin were measured. Values are the means \pm SEM $(\mathrm{n}=3)$. Scale bar, $20 \mu \mathrm{m}$.

response to cytotoxic stimuli such as DNA damage, Bax activation requires $\mathrm{p} 53$-induced expression of the proapoptotic BH3-only Bcl-2 family member Puma. In response to other death stimuli, such as growth factor deprivation or death receptor signaling, other BH3-only proteins Bim and Bid are expressed as critical mediators of Bax/Bak-dependent cell death [35]. The mechanism of

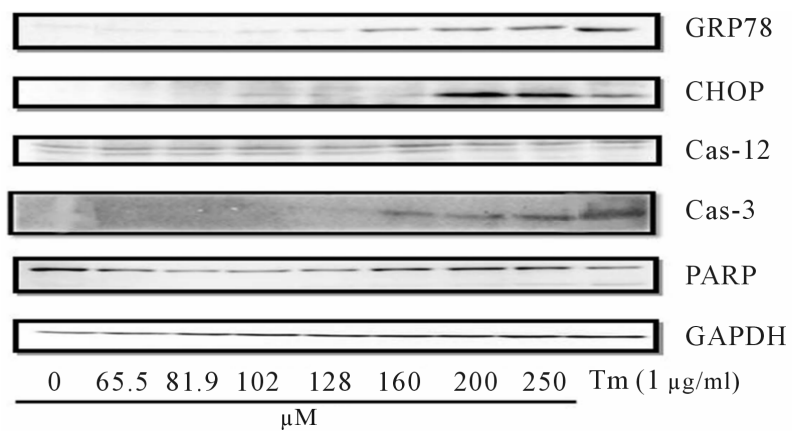

(a)

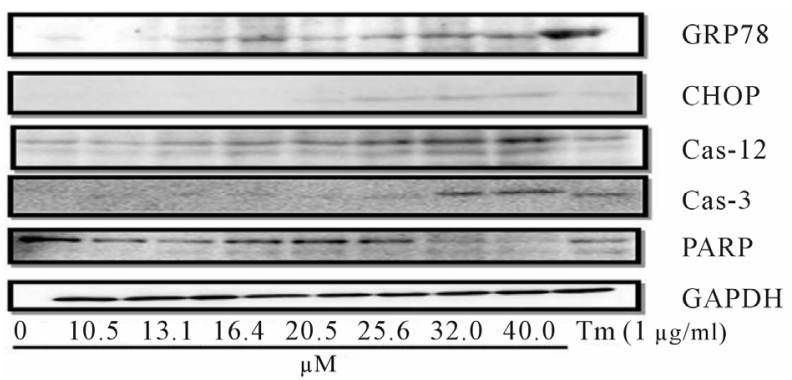

(b)

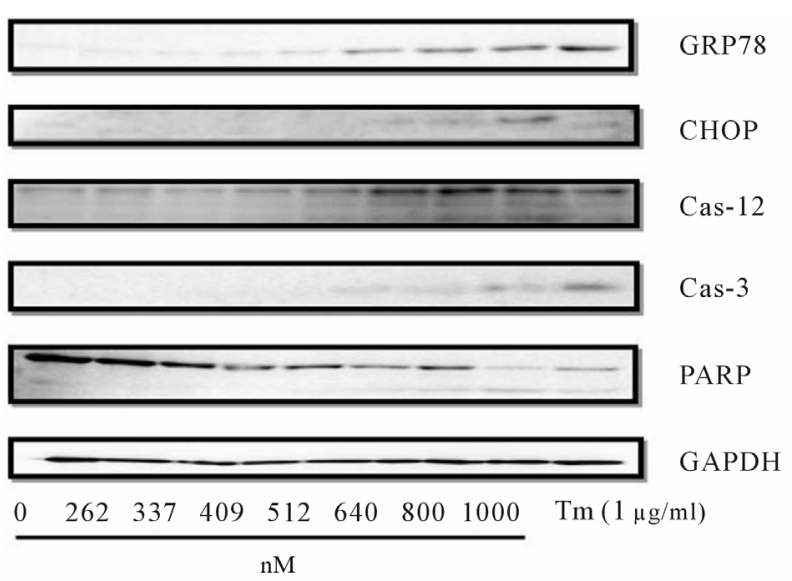

(c)

Figure 3. Western blot analysis of GRP78, caspase-12, caspase-3, CHOP and PARP in EDC-treated PC12 cells. Cells were cultured without (control) or with bisphenol A (a); $p$-nonylphenol (b); or tributyltin chloride (c) as described in Figure 1 and lysed. Twenty micrograms of total protein per lane was loaded onto an SDS-PAGE gel. Immunoblotting was carried out using specific antibodies for the indicated proteins. The results shown are representative of five independent experiments.

the pro-apoptotic action of Puma has been ascribed to its ability to bind with high affinity and consequently inhibit all anti-apoptotic Bcl-2 family members, including Bcl-2, Bcl-xL and Mcl-1 [36-40]. It has also been reported that Puma can activate the intrinsic apoptotic pathway by directly binding to Bax [39].

Puma has been identified as an ER stress-responsive 
gene in a previous global gene expression profiling study $[41,42]$ and in an siRNA library screening of genes that inhibit ER stress-induced apoptosis [43]. Puma is induced by ER stress in a variety of cell types [44-46]. The induction of Puma in response to ER stress is p53-independent in most cases, and mediated in part by the transcription factors CHOP [47], E2F1[43] and TRB3 [48]. It is likely that other transcription factors also contribute to the upregulation of Puma inducing by ER stress. Apoptosis induced by ER poisons tumicamycin and thapsigargin is inhibited in Puma-knockout HCT 116 colon cancer cells [41,44], Puma-knockdown cardiomyocytes [46] and neuronal cells [48], and Puma-knockout MEF cells [47]. At the same time, other BH3-only proteins such as Bim are also critical in ER stress-induced apoptosis in other cell types [47,49]. A deficiency in Puma or Bim protects motor neurons from ER stress-induced apoptosis and delays motor neuron loss in an amyotrophic lateral sclerosis mouse model [50,51], suggesting that Puma and Bim have overlapping functions in neurodegeneration [40]. Therefore, the observed upregulation of Puma or Bim induced by the three EDCs, as shown in Figures 4(a)-(c), strongly suggests that these compounds trigger ER stress-mediated apoptosis in cultured PC12 cells as a neuronal culture model system.

To confirm whether the three apoptosis-inducing EDCs indeed induce ER stress, we measured the accumulation of unfolded proteins by transfecting the PC12 cells with cDNA encoding the cystic fibrosis transmembrane conductance regulator (CFTR) harboring the $\Delta \mathrm{F} 508$ mutation, which is a marker of the accumulation of unfolded proteins in the ER during ER stress [52]. The unfolded protein response (UPR) mechanism aids cellular recovery by increasing the proteolytic capacity of the cell and thereby decreasing the accumulated protein load within the ER. The $\triangle 508$ mutation in the CFTR gene produces an unfolded protein, which is then completely retained in the ER and not degraded [53]. This is believed to a result of subcellular mislocalization of the CFTR $\triangle 508$ protein, as visualized using immunohistochemical staining. These observations led to a hypothesis that the CFTR $\triangle 508$ mutation leads to accumulation of the protein in the ER when the UPR is activated $[53,54]$. As shown in Figure 5, we found that the CFTR $\triangle 508$ protein did accumulate in the ER in PC12 cells treated with the three apoptosis-inducing EDCs. These results indicate that these three apoptosis-inducing EDCs indeed induce ER stress-mediated apoptosis in cultured PC12 cells.

Because the concentrations of the EDCs used in this study were markedly higher than their typical environmental levels, we compared the apoptosis-inducing activity and estrogen-like activity of these compounds in PC12 cells. We analyzed whether the apoptosis-inducing

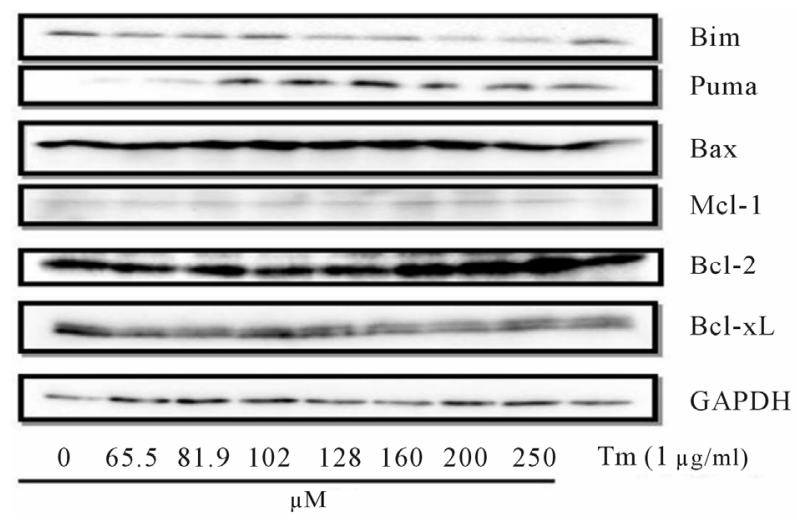

(a)

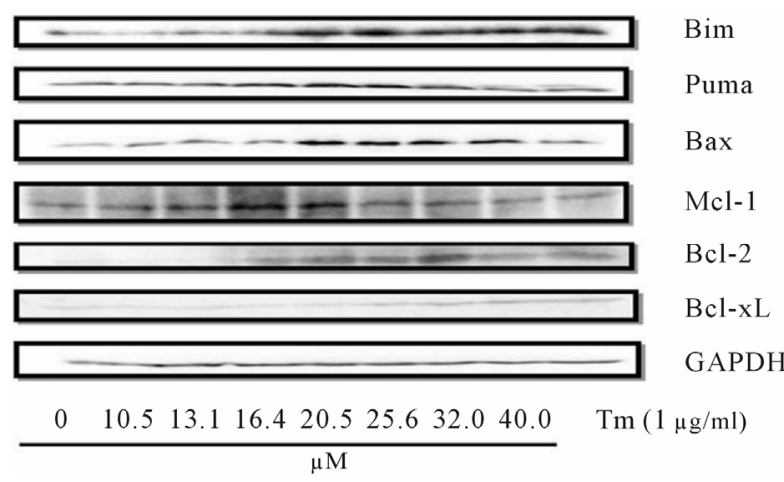

(b)

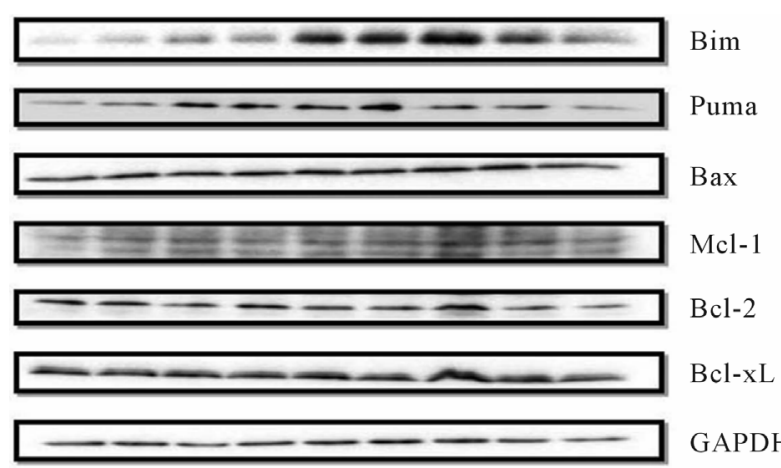

$\begin{array}{lllllllll}0 & 262 & 337 & 409 & 512 & 640 & 800 & 1000 & \mathrm{Tm}\end{array}(1 \mu \mathrm{g} / \mathrm{ml})$

$\mathrm{nM}$

(c)

Figure 4. Western blot analysis of Bcl-2, Bim, Bcl-xL, Mcl-1, Puma and Bim proteins in EDC-treated PC12 cells. Cells were cultured without (control) or with bisphenol A (a), p-nonylphenol (b) or tributyltin chloride (c) and were lysed as described in Figure 3. Twenty micrograms of total protein per lane were resolved by SDS-PAGE. Immunoblotting was then carried out using specific antibodies for the indicated proteins. The results shown are representative of five independent experiments.

EDCs have estrogenic effects at concentrations lower than those required to induce apoptosis in cultured PC12 cells transfected with a luciferase reporter under the 


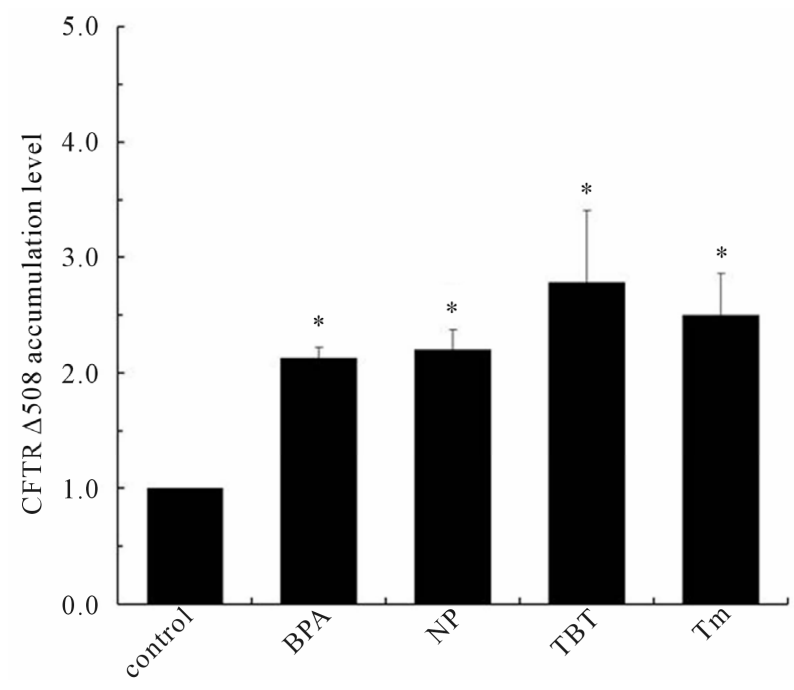

Figure 5. EDCs induce the accumulation of unfolded proteins in the ER. PC12 cells were transfected with the pEGFPCFTR $\triangle$ F508 expression plasmid and cultured for $48 \mathrm{~h}$. The medium was then replaced with serum-free DMEM containing the indicated EDC as necessary. The cells were then treated without (control) or with $160 \mu \mathrm{M} \mathrm{BPA}, 25.6 \mu \mathrm{M} \mathrm{NP}, 640 \mathrm{nM}$ TBT or $1 \mu \mathrm{g} / \mathrm{ml} \mathrm{Tm}$. After cultivation for $24 \mathrm{~h}$, the cells were collected and the accumulated unfolded proteins were quantified by determining the number of strongly GFP-positive cells by flow cytometry. The values shown are the means \pm SEM ( $n$ $=4$ ). Significant differences between groups were assessed using the Student's t-test. ${ }^{*} \mathrm{P}<0.05$ vs. control.

control of estrogen receptor $\alpha$. As shown in Figures 6(a) and (b), BPA displayed estrogenic effects $\left(\mathrm{EC}_{50}=5.9\right.$ $\mu \mathrm{M})$, but NP and TBT (data not shown) did not, in the transfected PC12 cells. Although BPA has both ER stress-associated apoptosis-inducing and estrogen-like effects at high concentrations, it shows only estrogen-like effects at low concentrations.

These results suggest that BPA may mainly exert estrogenic effects and that other EDCs may principally exert apoptosis-inducing effects upon exposure of cells to these compounds as environmental pollutants.

In our previous report, we observed that NP induces ER stress-mediated apoptosis and NGF protects against this response in neuronally differentiated PC12 cells [3]. In our current study, we investigated whether NGF could prevent EDC-induced apoptosis in naive PC12 cells. As shown in Figure 7, NGF suppresses apoptosis induced by the three apoptosis-inducing EDCs. In this regard, we have reported that the PI3-K/Akt and Ras/MARK signaling pathways promote the survival of cultured neurons and PC12 cells [3].

Apoptosis is involved in the developmental processes of almost all vertebrates and also the maintenance of body homeostasis by allowing cells to die without the need to mobilize macrophages. However, apoptosis is also observed in some neurodegenerative disorders, for

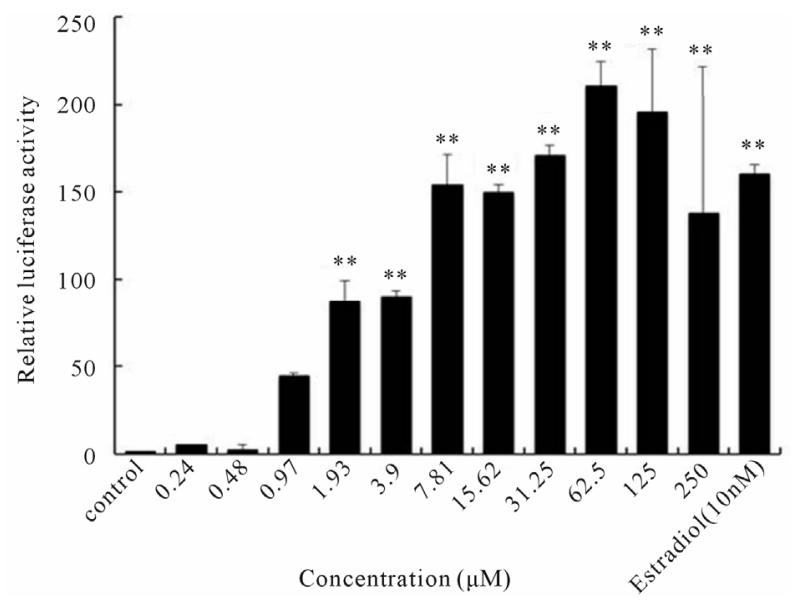

(a)

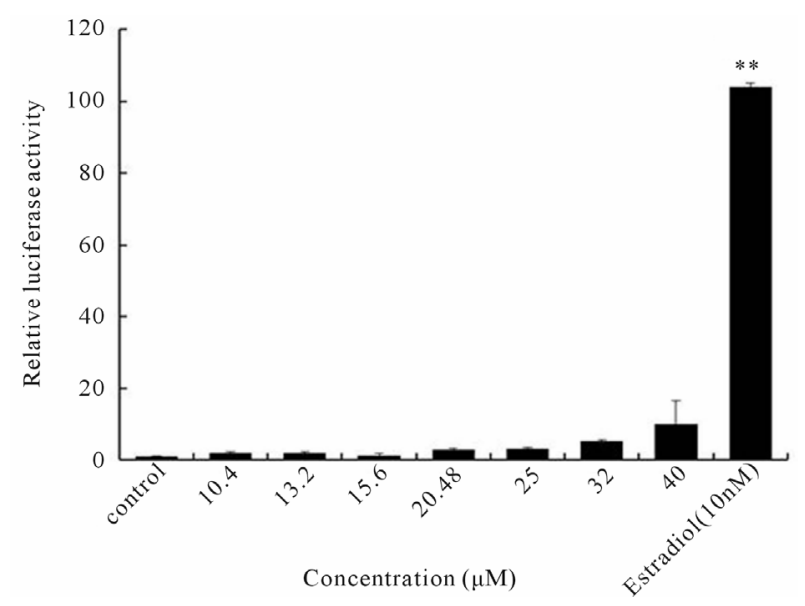

(b)

Figure 6. Estrogenic effects of EDCs on PC12 cells. PC12 cells were transfected with the expression plasmids pGLrER $\alpha$, pERE-AUG100-Luc ${ }^{+}$and phTK-Luc ${ }^{+}$(control plasmid). pEREAUG100-Luc ${ }^{+}$contains an estrogen-responsive element (ERE) upstream of its CMV promoter which directs the transcription of the luciferase gene. The transfected cells were cultured for $48 \mathrm{~h}$ and the medium was then replaced with serum-free DMEM without or with BPA (a) or NP (b). The final concentrations of the EDCs and of control estradiol are indicated. After cultivation for $24 \mathrm{~h}$, the cells were collected and cell lysates were prepared and assayed for luciferase activity. Significant differences between groups were assessed using Tukey's test. ${ }^{* * *} \mathrm{P}<0.01$ vs. control.

instance, Alzheimer's, Parkinson's and Huntington's diseases. The molecular mechanisms of apoptosis comprise the activation of pro-apoptotic Bcl-2 family members, the activation of the caspase cascade and the fragmentation of DNA [55]. We found also in our present experiments that NGF suppresses EDC-induced apoptosis concomitantly with the suppression EDC-induced ER stress-mediated signaling (data not shown). Hence, EDC-induced apoptosis is likely to incorporate ER stress-mediated signaling. 


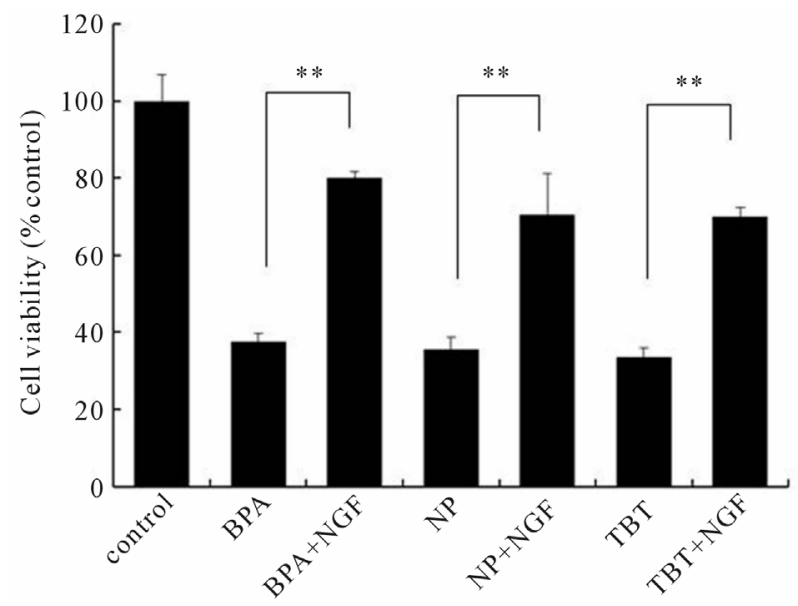

Figure 7. NGF suppresses EDC-induced apoptosis in $\mathrm{PC} 12$ cells. PC12 cells were cultured for $24 \mathrm{~h}$ without (control) or with $160 \mu \mathrm{M}$ BPA, $25.6 \mu \mathrm{M}$ NP or $640 \mathrm{nM}$ TBT in serum-free DMEM in the absence or presence of $100 \mu \mathrm{M}$ NGF (+NGF). Viable cells were then quantified using the MTT assay. The values shown are the means \pm SEM $(n=4)$. Differences between groups were examined for statistical significance using the Student's t-test. ${ }^{* *} \mathrm{P}<0.01$ vs. control.

\section{DISCUSSION}

It has been suggested previously that BPA functions either estrogenically or anti-estrogenically when binding in vitro to estrogen receptor $\alpha$ in competition with estradiol [11]. The relative binding affinity of BPA to estrogen receptor $\alpha$ is known to be more than 1000 times weaker than that of estradiol. Nevertheless, there is some evidence that BPA stimulates cellular responses at very low concentrations through various pathways [56-60]. In terms of transcriptional actions, xenoestrogens, but not $17 \beta$-estradiol, have been reported to enhance the expression of genes involved in mitochondrial oxidative phosphorylation [60]. We found in our current experiments that BPA indeed has estrogenic action in cultured cells at a concentration lower than that required to induce ER stress-associated apoptosis, suggesting that BPA may mainly exert estrogenic effects on cells in the body as an environmental pollutant (Figure 6(a)). We consider that the estrogenic effect of BPA is caused by its binding to estrogen receptor $\alpha$ because no significantly increased luciferase activity was observed when the expression plasmid pGLrER $\alpha$ was omitted from plasmids transfected to PC12 cells (data not shown). On the other hand, a previous study has reported that fetal neonatal exposure to BPA has effects on brain development in mice [61].

We further found in our current study that TBT induces ER stress-associated apoptosis in cultured PC12 cells by upregulating the Bcl-2 family protein Bim (Figure 4(c)). It has been found previously that TBT induces an excessive increase in $\mathrm{Ca}^{2+}$ and apoptotic cell death in some types of neuronal cells [12,62-64]. It was also sug- gested in another report that TBT mobilizes intracellular $\mathrm{Ca}^{2+}$ in $\mathrm{PC} 12$ cells by enhancing the transmembrane influxes of $\mathrm{Ca}^{2+}$ [65]. Although the specific type of $\mathrm{Ca}^{2+}$ channel responsible for TBT-induced $\mathrm{Ca}^{2+}$ mobilization remains unknown, the possible causal relationship between $\mathrm{Ca}^{2+}$ mobilization and ER stress-associated apoptosis by TBT warrants further extensive evaluation in the future [66].

In our previous study using neuronally differentiated PC12 cells, we found that NP induces ER stress-associated apoptosis via an increase in the intracellular $\mathrm{Ca}^{2+}$ concentration and reduction in ERK1/2 phosphorylation [3]. In our current study, we investigated the pro-apoptotic mechanism of NP in naive PC12 cells by measuring cell viability. As shown in Figure 1(b), NP decreases cell viability in a dose-dependent manner. It has been reported that apoptosis can be classified into at least two types, ordinary type and ER stress-mediated type and we here observed that NP led to ER stress-associated apoptosis because it induced the cleavage of ER stress-specific caspase-12, the expression of GRP78, and the accumulation of unfolded CFTR $\Delta 508$ protein.

Some investigators have reported the effects of NP and BPA on neuronal development, and found that EDCs significantly influence both dendritic and synaptic neuronal development [10]. NP and BPA have also been found to cause dendritic and synaptic developmental changes in hypothalamic neurons in the rat in which the exposure of newborn male and female rat pups to this EDC can adversely alter the development of reproductive organs, such as the seminal vesicle prostate glands and ovarian uterine horn [67]. Recently also, it was reported that exposure to the same dose of BPA during development results in a marked influence on synaptogenesis and on neuronal vulnerability in hippocampal cultures [68]. The details of endocrine-disrupting properties and behavioral effects of NP and BPA during the critical period of sexual differentiation in the brain remain unclear.

In appropriate environmental exposure to NP and BPA at neural development stage could potentially perturb the organizational activities of estrogen and the normal developmental processes of the neurons and glia in the hypothalamic area. Recently, it has been reported that the disruption of dopaminergic neuron development induced by prenatal and neonatal exposure to BPA can be mediated by non-hormonergic actions of BPA [69]. Furthermore, some investigators have reported that prenatal and neonatal exposure to BPA induces other behavioral abnormalities associated with the alternation not only of dopaminergic synthesis but also other neurotransmission processes [69]. Prenatal and neonatal exposure to BPA could therefore cause other behavioral abnormalities such as anxiogenic behavior, motor learning behavior and memory effects. Because the low-dose endocrine- 
disrupting action of various environmental toxins may be a serious problem, it was investigated whether exposure of the central nervous system of mice to low-dose BPA could induce behavioral abnormalities. A previous study has reported that treatment with low and high doses of BPA induces memory impairment [70,71]. Furthermore, these investigators also reported using immunohistochemistry that low and high doses of BPA markedly decrease the level of choline acetyltransferase (ChAT)-like immunoreactivity in widespread regions of the hippocampus as compared with the control. The widely accepted cholinergic function in the hippocampus is im- portant for learning and memory processes [69-71]. Among the cholinergic parameters described in the brains of Alzheimer's disease patients, the decrease in ChAT activity is the most prominent and provides an excellent biochemical correlation with the severity of dementia. The current evidence is strongly supportive of the notion that prenatal and neonatal exposure to BPA can induce dynamic morphological changes in cholinergic fibers, which is associated with the disruption of neuron development [71]. The extent of memory impairment corresponds well to the dysfunction of cholinergic neurons in the hippocampus of mice that have

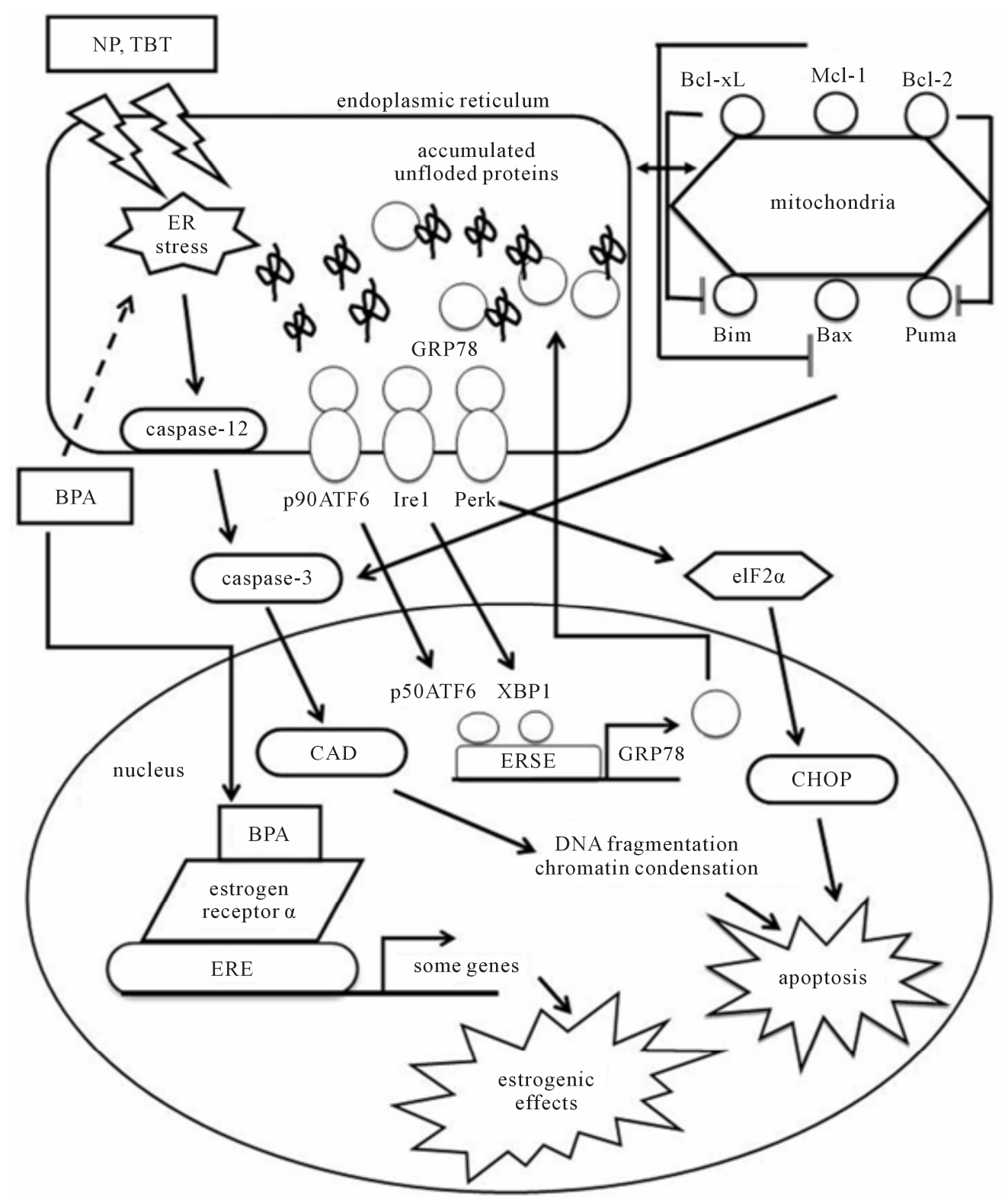

Figure 8. A proposed model for the actions of apoptosis-inducing EDCs in cells. NP and TBT are the apoptosis-inducing EDCs (AICs). BPA has estrogen-like effects at low concentrations, but has both estrogen-like effects and ER stress-associated apoptosis-inducing effects at high concentrations. See the text for details. 
been both prenatally and neonatally exposed to BPA [71].

Previously we reported that NP induces apoptosis whereas NGF suppresses it in neuronally differentiated PC12 cells. We also observed in our present study that NGF prevents EDC-induced apoptosis (Figure 7). Neurotrophins such as NGF and BDNF (brain-derived neurotrophic factor) play vital roles not only in neuronal growth and differentiation but also in the prevention of neuronal death. The neurotrophins manifest their effects by binding to two discrete receptor subtypes, the tropomyosin receptor kinase (Trk) family and the p75 neurotrophin receptor $\left(\mathrm{p} 75^{\mathrm{NTR}}\right)$. NGF not only plays a role in the differentiation of neuronal cells but also acts as an anti-apoptotic factor against certain stimuli, including chemical compounds. We have reported previously in this regard that both the NGF-induced PI3-K/Akt and Ras/MARK signaling pathways promote the survival of cultured PC12 cells [3].

We used an in vitro assay system involving PC12 cells in our current experiments and exposed these cells for only 24 hours to EDC concentrations that are higher than those found in the environment. We also observed similar apoptosis-inducing effects of EDCs on other cell types such as COS7 cells (data not shown). We realize that the EDC concentrations we have used in our analyses are very high compared with those found in the environment but note that the observed estrogenic concentration of BPA is also high compared with its concentration in the environment (Figure 6(a)). Moreover, EDCs may have apoptotic effects on neurons and other organs upon their accumulation in the body or via their condensation through the food chain [72]. The detailed molecular mechanisms of their effects remain to be fully elucidated.

In summary, we here demonstrate that EDCs induce apoptosis in cultured PC12 cells and can be classified into three groups, a group that induces ER stress-associated apoptosis and activates the UPR system, a group that induces non-ER stress-associated apoptosis, and a group that does not induce apoptosis in PC12 cells. We additionally found that BPA has estrogen-like effects, but that NP, TBT or beno do not, in PC12 cells transfected with a luciferase reporter plasmid that is activated by estrogen receptor $\alpha$. These results suggest that BPA may predominantly exert estrogenic effects, but that the other EDCs we tested may have mainly apoptosis-inducing effects on cells when they are present as environmental pollutants (Figure 8). The apoptosis-inducing EDCs may influence some proteins in the ER including ER membrane to perturb its homeostasis and induce ER stressassociated apoptosis. We propose to designate the apoptosis-inducing EDCs as apoptosis-inducing chemicals (AICs) [3].

\section{ACKNOWLEDGEMENTS}

We thank Mr. Y. Fukushima and Mr. K. Sugihara for helpful discussions. We are grateful to Dr. M. Takeyoshi (Chemicals Evaluation and Research Institute, Tokyo, Japan) for generously providing the expression plasmids pGLrERá and pERE-AUG100-Luc ${ }^{+}$and Dr. Ron R. Kopito (Stanford University, Stanford, CA) for providing the expression plasmid pEGFP-CFTR $\Delta 508$. This work was supported by grantsin-aid for scientific research from MEXT (Ministry of Education, Culture, Sports, Science and Technology of Japan) and Program for the Strategic Research Foundation (2008-2012) from MEXT, and from Kansai University (Grant-in-Aid for Joint Research, 2011-2012).

\section{REFERENCES}

[1] Crisp, T.M., Clegg, E.D., Cooper, R.L., et al. (1998) Environmental endocrine disruption: An effects assessment and analysis. Environmental Health Perspectives, 106, 11-56.

[2] Newbold, R.R., Hanson, R.B., Jefferson, W.N., et al. (2000) Proliferative lesions and reproductive tract tumors in male descendants of mice exposed developmentally to diethylstilbestrol. Carcinogenesis, 21, 1355-1363. doi:10.1093/carcin/21.7.1355

[3] Kusunoki, T., Shimoke, K., Komatsubara, S., et al. (2008) $p$-Nonylphenol induces endoplasmic reticulum stress-mediated apoptosis in neuronally differentiated PC12 cells. Neuroscience Letters, 431, 256-261. doi:10.1016/j.neulet.2007.11.058

[4] Gass, J.N., Jiang, H.Y., Wek, R.C., et al. (2008) The unfolded protein response of B-lymphocytes: PERK-independent development of antibody-secreting cells. Molecular Immunology, 45, 1035-1043. doi:10.1016/j.molimm.2007.07.029

[5] Lipson, K.L., Fonseca, S.G., Ishigaki, S., et al. (2006) Regulation of insulin biosynthesis in pancreatic beta cells by an endoplasmic reticulum-resident protein kinase IRE1. Cell Metabolism, 4, 245-254. doi:10.1016/j.cmet.2006.07.007

[6] Bertolotti, A., Zhang, Y., Hendershot, L.M., et al. (2000) Dynamic interaction of BiP and ER stress transducers in the unfolded-protein response. Nature Cell Biology, 2, 326-332. doi:10.1038/35014014

[7] Ye, J., Rawson, R.B., Komuro, R., et al. (2000) ER stress induces cleavage of membrane-bound ATF6 by the same proteases that process SREBPs. Molecular Cell, 6, 13551364. doi:10.1016/S1097-2765(00)00133-7

[8] Kanekura, K., Suzuki, H., Aiso, S., et al. (2009) ER stress and unfolded protein response in amyotrophic lateral sclerosis. Molecular Neurobiology, 39, 81-89. doi:10.1007/s12035-009-8054-3

[9] Talmage, D.A. and Listerud, M. (1994) Retinoic acid suppresses polyoma virus transformation by inhibiting transcription of the c-fos proto-oncogene. Oncogene, $\mathbf{9}$, 3557-3563.

[10] Sakamoto, H., Mezaki, Y., Shikimi, H., et al. (2003) Dendritic growth and spine formation in response to es- 
trogen in the developing Purkinje cell. Endocrinology, 144, 4466-4477. doi:10.1210/en.2003-0307

[11] Hiroi, T., Okada, K., Imaoka, S., et al. (2006) Bisphenol A binds to protein disulfide isomerase and inhibits its enzymatic and hormone-binding activities. Endocrinology, 147, 2773-2780. doi:10.1210/en.2005-1235

[12] Okada, Y., Oyama, Y., Chikahisa, L., et al. (2000) Tri-nbutyltin-induced change in cellular level of glutathione in rat thymocytes: A flow cytometric study. Toxicology Letters, 117, 123-128. doi:10.1016/S0378-4274(00)00237-X

[13] Antizar-Ladislao, B. (2008) Environmental levels, toxicity and human exposure to tributyltin (TBT)-contami-nated marine environment. A review. Environment International, 34, 292-308. doi:10.1016/j.envint.2007.09.005

[14] Gardiner, J.A., Kirkland, J.J., Klopping, H.L., et al. (1974) Fate of benomyl in animals. Journal of Agricultural and Food Chemistry, 22, 419-427. doi:10.1021/jf60193a046

[15] Lim, J. and Miller, M.G. (1997) The role of the benomyl metabolite carbendazim in benomyl-induced testicular toxicity. Toxicology and Applied Pharmacology, 142, 401410. doi:10.1006/taap.1996.8042

[16] Zbozinek, J.V. (1984) Environmental transformations of DPA, SOPP, benomyl, and TBZ. Residue Reviews, 92, 113-155.

[17] Lavy, T.L., Mattice, J.D., Massey, J.H., et al. (1993) Measurements of year-long exposure to tree nursery workers using multiple pesticides. Archives of Environmental Contamination and Toxicology, 24, 123-144. doi:10.1007/BF01141339

[18] Davidse, L.C. and Flach, W. (1977) Differential binding of methyl benzimidazol-2-yl carbamate to fungal tubulin as a mechanism of resistance to this antimitotic agent in mutant strains of Aspergillus nidulans. Journal of Cell Biology, 72, 174-193. doi:10.1083/jcb.72.1.174

[19] Laskey, J.W., Rehnberg, G.L., Hein, J.F., et al. (1982) Effects of chronic manganese $\left(\mathrm{Mn}_{3} \mathrm{O}_{4}\right)$ exposure on selected reproductive parameters in rats. Journal of Toxicology and Environmental Health, 9, 677-687. doi:10.1080/15287398209530195

[20] Barnes, T.B., Verlangieri, A.J. and Wilson, M.C. (1983) Reproductive toxicity of methyl-1-(butylcarbamoyl)-2benzimidazole carbamate (benomyl) in male Wistar rats. Toxicology, 28, 103-115. doi:10.1016/0300-483X(83)90110-5

[21] Linder, R.E., Rehnberg, G.L. and Strader, L.F., et al. (1988) Evaluation of reproductive parameters in adult male Wistar rats after subchronic exposure (gavage) to benomyl. Journal of Toxicology and Environmental Health, 25, 285-298. doi:10.1080/15287398809531210

[22] Hess, R.A., Moore, B.J., Forrer, J., et al. (1991) The fungicide benomyl (methyl 1-(butylcarbamoyl)-2-benzi-midazolecarbamate) causes testicular dysfunction by inducing the sloughing of germ cells and occlusion of efferent ductules. Fundamental and Applied Toxicology, 17, 733745. doi:10.1016/0272-0590(91)90181-3

[23] Klotz, D.M., Beckman, B.S., Hill, S.M., et al. (1996) Identification of environmental chemicals with estrogenic activity using a combination of in vitro assays. Environmental Health Perspectives, 104, 1084-1089.

\section{doi:10.1289/ehp.961041084}

[24] Yamada, T., Sumida, K., Saito, K., et al. (2005) Functional genomics may allow accurate categorization of the benzimidazole fungicide benomyl: Lack of ability to act via steroid-receptor-mediated mechanisms. Toxicology and Applied Pharmacology, 205, 11-30. doi:10.1016/j.taap.2004.09.002

[25] Vig, B.K., Yoo, H.J. and Schiffmann, D. (1991) Kinetochore proteins, peripheral location of chromosomes and nuclear budding: Another look at the genesis of aneuploidy. Mutagenesis, 6, 361-367. doi:10.1093/mutage/6.5.361

[26] Hewitt, M.J., Mutch, P. and Pratten, M.K. (2005) Potential teratogenic effects of benomyl in rat embryos cultured in vitro. Reproductive Toxicology, 20, 271-280. doi:10.1016/j.reprotox.2005.02.003

[27] Lee, K.M., Yang, W., Rhee, J.S., et al. (2010) Effects of endocrine disruptors on Bombina orientalis P450 aromatase activity. Zoological Science, 27, 338-343. doi: $10.2108 / \mathrm{zsj} .27 .338$

[28] Sasaya, H., Utsumi, T., Shimoke, K., et al. (2008) Nicotine suppresses tunicamycin-induced, but not thapsigargin-induced, expression of GRP78 during ER stress-mediated apoptosis in PC12 cells. Journal of Biochemistry, 144, 251-257. doi:10.1093/jb/mvn063

[29] Jung-Testas, I. and Baulieu, E.E. (1998) Steroid hormone receptors and steroid action in rat glial cells of the central and peripheral nervous system. Journal of Steroid Biochemistry and Molecular Biology, 65, 243-251. doi:10.1016/S0960-0760(97)00191-X

[30] McEwen, B. (2002) Estrogen actions throughout the brain. Recent Progress in Hormone Research, 57, 357-384. doi:10.1210/rp.57.1.357

[31] Pretorius, E. and Bornman, M.S. (2005) Calcium-mediated aponecrosis plays a central role in the pathogenesis of estrogenic chemical-induced neurotoxicity. Medical Hympothese, 65, 893-904. doi:10.1016/j.mehy.2005.03.032

[32] Nakagawa, T., Zhu, H., Morishima, N., et al. (2000) Caspase-12 mediates endoplasmic-reticulum-specific apoptosis and cytotoxicity by amyloid-beta. Nature, 403, 98-103. doi: $10.1038 / 47513$

[33] Danial, N.N. (2007) BCL-2 family proteins: Critical checkpoints of apoptotic cell death. Clinical Cancer Research, 13, 7254-7263. doi:10.1158/1078-0432.CCR-07-1598

[34] Young, C., Klocke, B.J., Tenkova, T., et al. (2003) Ethanolinduced neuronal apoptosis in vivo requires BAX in the developing mouse brain. Cell Death and Differentiation, 10, 1148-1155. doi:10.1038/sj.cdd.4401277

[35] Akhtar, R.S., Ness, J.M. and Roth, K.A. (2004) Bcl-2 family regulation of neuronal development and neurodegeneration. Biochimica et Biophysica Acta, 1644, 189-203. doi:10.1016/j.bbamcr.2003.10.013

[36] Kuwana, T., Bouchier-Hayes, L., Chipuk, J.E., et al. (2005) BH3 domains of BH3-only proteins differentially regulate Bax-mediated mitochondrial membrane permeabilization both directly and indirectly. Molecular Cell, 17, 525-535. doi:10.1016/j.molcel.2005.02.003

[37] Willis, S.N., Fletcher, J.I., Kaufmann, T., et al. (2007) 
Apoptosis initiated when $\mathrm{BH} 3$ ligands engage multiple Bcl-2 homologs, not Bax or Bak. Science, 315, 856-859. doi:10.1126/science.1133289

[38] Chipuk, J.E., Fisher, J.C., Dillon, C.P., et al. (2008) Mechanism of apoptosis induction by inhibition of the antiapoptotic BCL-2 proteins. Proceedings of the National Academy of Sciences of the United States of America, 105, 20327-20332. doi:10.1073/pnas.0808036105

[39] Ming, L., Wang, P., Bank, A., et al. (2006) PUMA Dissociates $\mathrm{Bax}$ and $\mathrm{Bcl}-\mathrm{X}(\mathrm{L})$ to induce apoptosis in colon cancer cells. Journal of Biological Chemistry, 281, 1603416042. doi:10.1074/jbc.M513587200

[40] Yu, J. and Zhang, L. (2008) PUMA, a potent killer with or without p53. Oncogene, 27, 71-83.

doi:10.1038/onc.2009.45

[41] Reimertz, C., Kogel, D., Rami, A., et al. (2003) Gene expression during ER stress-induced apoptosis in neurons: Induction of the $\mathrm{BH} 3$-only protein Bbc3/PUMA and activation of the mitochondrial apoptosis pathway. Journal of Cell Biology, 162, 587-597. doi:10.1083/jcb.200305149

[42] Ward, M.W., Kogel, D. and Prehn, J.H. (2004) Neuronal apoptosis: BH3-only proteins the real killers? Journal of Bioenergetics and Biomembranes, 36, 295-298. doi:10.1023/B:JOBB.0000041756.23918.11

[43] Futami, T., Miyagishi, M. and Taira, K. (2005) Identification of a network involved in thapsigargin-induced apoptosis using a library of small interfering RNA expression vectors. Journal of Cell Biology, 280, 826-831.

[44] Luo, X., He, Q., Huang, Y., et al. (2005) Transcriptional upregulation of PUMA modulates endoplasmic reticulum calcium pool depletion-induced apoptosis via Bax activetion. Cell Death \& Differentiation, 12, 1310-1318. doi:10.1038/sj.cdd.4401659

[45] Jiang, C.C., Lucas, K., Avery-Kiejda, K.A., et al. (2008) Up-regulation of Mcl-1 is critical for survival of human melanoma cells upon endoplasmic reticulum stress. Cancer Research, 68, 6708-6717. doi:10.1158/0008-5472.CAN-08-0349

[46] Nickson, P., Toth, A. and Erhardt, P. (2007) PUMA is critical for neonatal cardiomyocyte apoptosis induced by endoplasmic reticulum stress. Cardiovascular Research, 73, 48-56. doi:10.1016/j.cardiores.2006.10.001

[47] Li, J., Lee, B. and Lee, A.S. (2006) Endoplasmic reticulum stress-induced apoptosis: Multiple pathways and activation of p53-up-regulated modulator of apoptosis (PUMA) and NOXA by p53. Journal of Cell Biology, 281, 72607270 .

[48] Zou, C.G., Cao, X.Z., Zhao, Y.S., et al. (2009) The molecular mechanism of endoplasmic reticulum stress- induced apoptosis in PC-12 neuronal cells: The protective effect of insulin-like growth factor I. Endocrinology, 150, 277-285. doi:10.1210/en.2008-0794

[49] Puthalakath, H., O'Reilly, L.A., Gunn, P., et al. (2007) ER stress triggers apoptosis by activating BH3-only protein Bim. Cell, 129, 1337-1349. doi:10.1016/j.cell.2007.04.027

[50] Hetz, C., Thielen, P., Fisher, J., et al. (2007) The proapop- totic BCL-2 family member BIM mediates motoneuron loss in a model of amyotrophic lateral sclerosis. Cell Death \& Differentiation, 14, 1386-1389. doi:10.1038/sj.cdd.4402166

[51] Kieran, D., Woods, I., Villunger, A., et al. (2007) Deletion of the BH3-only protein puma protects motoneurons from ER stress-induced apoptosis and delays motoneuron loss in ALS mice. Proceedings of the National Academy of Sciences of the United States of America, 104, 2060620611. doi:10.1073/pnas.0707906105

[52] Ward, C.L. and Kopito, R.R. (1994) Intracellular turnover of cystic fibrosis transmembrane conductance regulator. Inefficient processing and rapid degradation of wild-type and mutant proteins. Journal of Biological Chemistry, 269, 25710-25718.

[53] Kerbiriou, M., Teng, L., Benz, N., et al. (2009) The calpain, caspase 12 , caspase 3 cascade leading to apoptosis is altered in F508del-CFTR expressing cells. PLoS One, 4, e8431-e8436. doi:10.1371/journal.pone.0008436

[54] Kerbiriou, M., Le Drevo, M.A., Ferec, C., et al. (2007) Coupling cystic fibrosis to endoplasmic reticulum stress: Differential role of Grp78 and ATF6. Biochimica et Biophysica Acta, 1772, 1236-1249.

[55] Rao, R.V. and Bredesen, D.E. (2004) Misfolded proteins, endoplasmic reticulum stress and neurodegeneration. Current Opinion in Cell Biology, 16, 653-662. doi:10.1016/j.ceb.2004.09.012

[56] Kurosawa, T., Hiroi, H., Tsutsumi, O., et al. (2002) The activity of bisphenol A depends on both the estrogen receptor subtype and the cell type. Endocrine Journal, 49, 465-471. doi:10.1507/endocrj.49.465

[57] Kuiper, G.G., Lemmen, J.G., Carlsson, B., et al. (1998) Interaction of estrogenic chemicals and phytoestrogens with estrogen receptor beta. Endocrinology, 139, 4252 4263. doi:10.1210/en.139.10.4252

[58] Gould, J.C., Leonard, L.S., Maness, S.C., et al. (1998) Bisphenol A interacts with the estrogen receptor alpha in a distinct manner from estradiol. Molecular and Cellular Endocrinology, 142, 203-214. doi:10.1016/S0303-7207(98)00084-7

[59] Iso, T., Watanabe, T., Iwamoto, T., et al. (2006) DNA damage caused by bisphenol A and estradiol through estrogenic activity. Biological and Pharmaceutical Bulletin, 29, 206-210. doi:10.1248/bpb.29.206

[60] Shioda, T., Chesnes, J., Coser, K.R., et al. (2006) Importance of dosage standardization for interpreting transcriptomal signature profiles: Evidence from studies of xenoestrogens. Proceedings of the National Academy of Sciences of the United States of America, 103, 1203312038. doi:10.1073/pnas.0605341103

[61] Tando, S., Itoh, K., Yaoi, T., et al. (2007) Effects of preand neonatal exposure to bisphenol A on murine brain development. Brain and Development, 29, 352-356. doi:10.1016/j.braindev.2006.10.003

[62] Viviani, B., Rossi, A.D., Chow, S.C., et al. (1995) Organotin compounds induce calcium overload and apoptosis in PC12 cells. Neurotoxicology, 16, 19-25.

[63] Mizuhashi, S., Ikegaya, Y. and Matsuki, N. (2000) Cyto- 
toxicity of tributyltin in rat hippocampal slice cultures. $\mathrm{Neu}$ roscience Research, 38, 35-42. doi:10.1016/S0168-0102(00)00137-1

[64] Nakatsu, Y., Kotake, Y. and Ohta, S. (2006) Tributyltininduced cell death is mediated by calpain in PC12 cells. Neurotoxicology, 27, 587-593. doi:10.1016/j.neuro.2006.03.010

[65] Gennari, A., Viviani, B., Galli, C.L., et al. (2000) Organotins induce apoptosis by disturbance of $[\mathrm{Ca}(2+)](\mathrm{i})$ and mitochondrial activity, causing oxidative stress and activation of caspases in rat thymocytes. Toxicology and Applied Pharmacology. 169, 185-190. doi:10.1006/taap.2000.9076

[66] Unno, T., Iida, R., Okawa, M., et al. (2009) Tributyltin-induced $\mathrm{Ca}(2+)$ mobilization via L-type voltage-dependent $\mathrm{Ca}(2+)$ channels in $\mathrm{PC} 12$ cells. Environmental Toxicology and Pharmacology, 28, 70-77. doi:10.1016/j.etap.2009.02.006

[67] Lee, P.C. (1998) Disruption of male reproductive tract development by administration of the xenoestrogen, nonylphenol, to male newborn rats. Endocrine, 9, 105-111. doi:10.1385/ENDO:9:1:105

[68] Yokosuka, M., Ohtani-Kaneko, R., Yamashita, K., et al.
(2008) Estrogen and environmental estrogenic chemicals exert developmental effects on rat hypothalamic neurons and glias. Toxicology in Vitro, 22, 1-9. doi:10.1016/j.tiv.2007.07.003

[69] Dutar, P., Bassant, M.H., Senut, M.C., et al. (1995) The septohippocampal pathway: Structure and function of a central cholinergic system. Physiological Reviews, 75, 393-427.

[70] Miyamoto, M., Kato, J., Narumi, S., et al. (1987) Characteristics of memory impairment following lesioning of the basal forebrain and medial septal nucleus in rats. Brain Research, 419, 19-31. doi:10.1016/0006-8993(87)90564-6

[71] Miyagawa, K., Narita, M., Akama, H., et al. (2007) Memory impairment associated with a dysfunction of the hippocampal cholinergic system induced by prenatal and neonatal exposures to bisphenol-A. Neuroscience Letters, 418, 236-241. doi:10.1016/j.neulet.2007.01.088

[72] Midoro-Horiuti, T., Tiwari, R., Watson, C.S., et al. (2010) Maternal bisphenol a exposure promotes the development of experimental asthma in mouse pups. Environmental Health Perspective, 118, 273-277. doi:10.1289/ehp.0901259

\section{ABBREVIATIONS}

AIC: Apoptosis-inducing chemical;

ATF6: Activating transcription factor 6;

BDNF: Brain-derived neurotrophic factor;

Beno: Benomyl;

BPA: Bisphenol A;

Bax: Bcl-2-associated X;

Bcl-2: B-cell CLL/lymphoma 2;

Bcl-xL: Bcl-2-like protein-1;

Bid: BH3 interacting domain death agonist;

Bim: Bcl-2-interacting mediator of cell death;

Puma: p53 up-regulated modulator of apoptosis;

Bak: Bcl-2 homologous antagonist;

CAD: Caspase-activated DNase;

CFTR: Cystic fibrosis transmembrane conductance regulator;

CHOP: C/EBP homologous protein;

EDC: Endocrine-disrupting chemical;
ER: Endoplasmic reticulum;

ERK1/2: Extracellular signal-regulated kinase 1/2;

GRP78: Glucose-regulated protein 78;

Ire1: Inositol-requiring transmembrane kinase and endonuclease 1;

Mcl-1: Myeloid cell leukemia sequence 1;

NGF: Nerve growth factor;

NP: $p$-nonylphenol;

NPE: Nonylphenol ethoxylates;

Perk: PKR-like ER kinase;

PARP: Poly (ADP-ribose) polymerase;

S1P: Site 1 protease;

S2P: Site 2 protease;

TBT: Tributyltin chloride;

Trk: Tropomyosin receptor kinase;

UPR: Unfolded protein response. 